\title{
Needs of older persons living in long-term care institutions: on the usefulness of cluster approach
}

Sławomir Tobis ${ }^{1 *}$ D, Krystyna Jaracz ${ }^{2}$, Sylwia Kropińska ${ }^{3}$, Dorota Talarska ${ }^{4}$, Juanita Hoe ${ }^{5}$, Katarzyna Wieczorowska-Tobis ${ }^{3}$ and Aleksandra Suwalska ${ }^{6}$

\begin{abstract}
Background: Long-term care units' residents do not constitute a homogeneous population. Providing effective care, tailored to individual needs, is crucial in this context. It can be facilitated by suitable tools and methods, which include needs assessment along with the physical, psychological and social aspects of care. We thus applied a cluster approach to identify their putative groupings to enable the provision of tailored care.

Methods: The needs of 242 residents of care homes in four Polish cities (Poznan, Wroclaw, Bialystok and Lublin), aged 75-102 years (184 females), with the Mini-Mental State Examination (MMSE) score $\geq 15$ points, were assessed with the CANE (Camberwell Assessment of Need for the Elderly) questionnaire. Their independence in activities of daily living was evaluated by the Barthel Index (BI), and symptoms of depression by the Geriatric Depression Scale (GDS). The results of MMSE, BI and GDS were selected as variables for K-means cluster analysis.

Results: Cluster 1 (C1), $n=83$, included subjects without dementia according to MMSE (23.7 \pm 4.4$)$, with no dependency $(\mathrm{Bl}=85.8 \pm 14.4)$ and no symptoms of depression ( $G D S=3.3 \pm 2.0)$. All subjects of cluster $2(C 2), n=87$, had symptoms of depression (GDS $=8.9 \pm 2.1)$, and their MMSE $(21.0 \pm 4.0)$ and $\mathrm{Bl}(79.8 \pm 15.1)$ were lower than those in C1 ( $p=0.006$ and $p=0.046$, respectively). Subjects of cluster $3(C 3), n=72$, had the lowest MMSE (18.3 \pm $3.1)$ and $\mathrm{BI}(30.6 \pm 18,8, p<0.001$ vs. $C 1 \& C 2)$. Their GDS $(7.6 \pm 2.3)$ were higher than $C 1(p<0.001)$ but lower than C2 $(p<0.001)$. The number of met needs was higher in C2 than in C1 $(10.0 \pm 3.2$ vs $8.2 \pm 2.7, p<0.001)$, and in C3 $(12.1 \pm 3.1)$ than in both $C 1$ and C2 $(p<0.001)$. The number of unmet needs was higher in C3 than in C1 $(1.2 \pm 1.5$ vs $0.7 \pm 1.0, p=0.015$ ). There were also differences in the patterns of needs between the clusters.

Conclusions: Clustering seems to be a promising approach for use in long-term care, allowing for more appropriate and optimized care delivery. External validation studies are necessary for generalized recommendations regarding care optimization in various regional perspectives.
\end{abstract}

Keywords: Needs, Care homes, Long-term care, Clusters, CANE

\footnotetext{
*Correspondence: stobis@ump.edu.pl

'Department of Occupational Therapy, Poznan University of Medical Sciences, ul. Swiecickiego 6, 60-781 Poznan, Poland

Full list of author information is available at the end of the article
}

(c) The Author(s). 2021 Open Access This article is licensed under a Creative Commons Attribution 4.0 International License, which permits use, sharing, adaptation, distribution and reproduction in any medium or format, as long as you give appropriate credit to the original author(s) and the source, provide a link to the Creative Commons licence, and indicate if changes were made. The images or other third party material in this article are included in the article's Creative Commons licence, unless indicated otherwise in a credit line to the material. If material is not included in the article's Creative Commons licence and your intended use is not permitted by statutory regulation or exceeds the permitted use, you will need to obtain permission directly from the copyright holder. To view a copy of this licence, visit http://creativecommons.org/licenses/by/4.0/. The Creative Commons Public Domain Dedication waiver (http://creativecommons.org/publicdomain/zero/1.0/) applies to the data made available in this article, unless otherwise stated in a credit line to the data. 


\section{Background}

At a certain point, many people, for various reasons, face the necessity to relocate to a care institution [1]. As long as they live in the community, they usually have a high level of engagement in occupational activities and purpose in life [2]. They are anxious about the prospect of moving and are afraid of being unable to carry on with their daily habits and routines [3]. A move to a care home is described as the final frontier, triggering negative and distressing thoughts and provoking strong feelings [4]. Modern and effective approaches to long-term care (LTC) that secure both the efficacy of care and the best possible comfort for the residents are subsequently required.

Once in an LTC institution, older people attempt to establish a home there. Four categories have been identified as critical to this process: continuity, preserving personal identity, belonging, and being active and working [5]. Maintaining these is not easy, as the institutional framework of LTC settings can limit and restrict older people's functioning [6]. Lack of autonomy upholds the stereotype of residents as (passive) recipients of care [7]. Behuniak states that the lack of control provokes a sense of powerlessness, and those with dementia are especially vulnerable [8]. The majority of residents in LTC units have dementia [9], and many of them report having a poor quality of life [10].

Residents of LTC facilities are commonly perceived as a relatively homogeneous group (usually physically unwell, with multiple functional deficits) [4], which is in contrast to the contemporary concept of providing individualized, person-centered care [11, 12]. As literature shows, LTC residents, in fact, constitute a diversified population [13, 14]. Providing effective care, tailored to individual needs, is crucial in this context [15] and can be facilitated by suitable tools and methods, which include needs assessment along with the physical, psychological and social aspects of care.

The Camberwell Assessment of Need for the Elderly (CANE) questionnaire can provide a basis for such an approach [16]. It encompasses the definition of need as a remediable deficit and includes both health and socioeconomic needs, which are essential for a holistic approach. An important advantage of CANE is its ability to distinguish between needs receiving adequate support (met needs) and those for which optimal interventions are missing (unmet needs). As far as LTC facilities are concerned, a number of studies using CANE have demonstrated that the total number of their residents' needs is generally high [17-20].

While each care setting's population presents a unique distribution of needs, there would be value in being able to categorize those needs (and, subsequently, the residents) within a few ranges (or groups), with the care provision in mind. We, therefore, applied a cluster approach to investigate whether distinct cognitive, functional and psychological profiles exist, which can distinguish the needs of residents. If so, this could create a starting point for assigning residents in respect of need-based groups. Such a distinction could be used to plan and improve the care provided and could enable precisely addressed interventions. The significance of implementing care models and services which are derived from the needs of older people has been recently stressed by Abdi et al. [21]

To the best of our knowledge, cluster analysis has never been used to characterize older people's needs assessed with CANE.

\section{Methods}

We applied a cluster approach to identify the putative groupings of LTC residents based on their scores in CANE and selected tools of Comprehensive Geriatric Assessment.

\section{The participants}

A total of 400 older individuals aged $\geq 75$ years, living in LTC institutions in four Polish cities (Poznan, Wroclaw, Bialystok and Lublin), were included in the study. The randomization and study protocol have been previously described in detail [20].

For the analysis, the data of 242 subjects with MiniMental State Examination (MMSE) score of at least 15 (adjusted for age and education), which was considered sufficient to understand the questions asked and give reliable answers [22], were included. The data comprised age and sex of the respondents, their education level and length of stay in the institution, as well as the scores of geriatric assessment tools (Barthel Index - BI, Geriatric Depression Scale - GDS, MMSE, and the results of the CANE questionnaire).

\section{The assessment tools}

BI was used for the assessment of dependence in basic activities of daily living [23]; the value of 80 points or more (out of the maximum of 100) was referred to as no dependence [24].

The short version of GDS (15 items) served as the screening tool for depression [25]. Subjects with at least 6 points (out of the maximum of 15) were classified as having symptoms of depression [26].

MMSE, a brief screening assessment tool, was used for detecting subjects with increased risk of dementia [27]. Possible scores range from 0 to 30 : $27-30$ being considered normal, 24-26 meaning mild cognitive impairment without dementia, 20-23 - mild dementia, and 15-19moderate dementia. Obtained scores were adjusted for age and education [28]. 
The CANE questionnaire is a comprehensive tool developed for the assessment of needs in older adults. Structured interviews were performed face-to-face by researchers trained using the CANE manual [16]. We used the Polish version of the questionnaire, which had been proven to have good psychometric properties in a pilot study [29].

The questionnaire covers a total of 24 areas of social, medical, psychological, and environmental needs, as well as two additional domains regarding caregivers (which were not analyzed in this article). Each area poses a question about a particular need. Responses are rated on a three-point scale where 0 means no need, 1 - met need (i.e., the problem is receiving or has received a proper intervention), and 2 - unmet need (i.e., the problem is left without appropriate intervention). For each participant, the numbers of met and unmet needs, as well as the number of all needs (sum of met and unmet needs), were calculated.

\section{Statistical analysis}

The statistical analysis was performed with STATISTI CA 13.0 (StatSoft, Poland) and SPSS software (IBM, Poland). For all characteristics analyzed, means and standard deviations were calculated. Normality in the data distribution was examined with the Shapiro-Wilk's test. Due to the lack of normality, medians were also presented. $P<0.05$ was considered to indicate statistical significance, and $p$ between 0.05 and $0.10-$ an insignificant trend.

\section{K-means cluster analysis}

$\mathrm{K}$-means clustering is a way to use data to uncover natural groupings within a heterogeneous population. To reveal the patterns, the algorithm starts by first assigning data points into random groups. The group centers are then calculated, and the group memberships are reassigned based on the distances between each data point and the group centers. This process is repeated until there are no changes in the group memberships from the previous iteration.

The results of the MMSE, BI and GDS were selected as variables for cluster analysis. K-means clustering was chosen as the clustering method since it is uniquely designed for non-hierarchical data partitioning (such as our data); in our case, it generated a small number of subgroups in studied LTC residents. As the abovementioned variables have been measured on different scales with different score ranges, all scores were transformed into z-scores before introducing them to the cluster analysis. Differences between cluster profiles were identified using $X^{2}$ for categorical variables and analyses of variance (F-tests) for continuous variables.

\section{Results}

The mean age of studied subjects was $83.1 \pm 5.9$ years (median: 83.0 years; range: $75-102$ years); 184 of them were females (76.0\%). The mean length of institutionalization was $73.2 \pm 66.7$ months (median: 60.0 months; range: 1 299 months). The mean BI was $67.2 \pm 29.0$ points (median: 75.0 points; range: $0-100$ points), MMSE $-21.4 \pm 4.5$ points (median: 21.0 points; range: $15-30$ points), and GDS $-6.6 \pm 3.2$ points (median: 7.0 points, range: $0-14$ points). Detailed characteristics of the studied group are presented in Table 1.

\section{Analysis of needs}

The mean number of needs in all studied subjects was $10.9 \pm 3.2$. Of these, a mean $10.0 \pm 3.1$ were met and $0.9 \pm 1.2$ - unmet needs. Met needs were observed for more than $90 \%$ of studied subjects in the following areas Looking after the home $(n=235-97.1 \%)$, Food $(n=234-$ 96.7\%) and Physical health ( $n=227-93.8 \%)$. Met needs were also commonly noted (i.e., $\geq 50 \%$ of studied subjects) for: Accommodation ( $n=217-89.7 \%)$, Self-care ( $n=179-74.8 \%), \quad$ Money/budgeting $\quad(n=154-63.6 \%)$, Mobility/falls and Continence (both $n=153-63.2 \%$ ), and Eyesight/hearing/communication $(n=141-53.8 \%)$. Unmet needs were most commonly reported for: Psychological distress $(n=42-17.4 \%)$, Company $(n=41-16.9 \%)$, Eyesight/hearing/communication and Intimate relationship (both $n=29-12.0 \%$ ), and Daytime activities ( $n=$ 28-11.6\%). In the remaining areas, unmet needs were recognized in no more than $10 \%$ of studied subjects.

\section{Cluster analysis}

Three clusters were identified based on concurrent analysis of the MMSE, BI and GDS scores.

Cluster 1 subjects $(n=83)$ had a mean MMSE score of $23.7 \pm 4.4$ points (i.e., above the cut-off point for dementia), BI score $-85.8 \pm 14.4$ (i.e., no dependency) and GDS score $-3.3 \pm 2.0$ (i.e., no symptoms of depression). In this cluster, 33 subjects (39.8\%) had MMSE scores within the normal range, and only 19 (22.9\%) scored below 20 points. Thirty-one individuals (37.3\%) had the maximum score in BI (100 points), whereas the minimum score of this group was 45 points. Moreover, only six subjects $(7.2 \%)$ of this cluster had symptoms of depression.

Cluster 2 subjects $(n=87)$ all had symptoms of depression; the mean GDS was $8.9 \pm 2.1$ points $(p<0.001$ vs cluster 1$)$. They had lower mean MMSE $(21.0 \pm 4.0$ points $-p=0.006)$ and lower mean BI $(79.8 \pm 15.1$ points $-p=0.046)$ compared to those of cluster 1 . Only 20 subjects $(23.0 \%)$ had MMSE scores in the normal range, and 25 (28.7\%) had these results below 20 points. For the BI, 13 participants (14.9\%) achieved the maximum score, and the minimum score was 40 . 
Table 1 The characteristics of studied subjects

\begin{tabular}{|c|c|c|}
\hline Parameter & Characteristic & n (\%) \\
\hline \multirow[t]{4}{*}{ Age } & $75-79$ years & $75(31.0)$ \\
\hline & $80-84$ years & $80(33.0)$ \\
\hline & $85-89$ years & $58(24.0)$ \\
\hline & $90+$ & $29(12.0)$ \\
\hline \multirow[t]{4}{*}{ Education } & Primary & $\begin{array}{l}112 \\
(46.3)\end{array}$ \\
\hline & Secondary & $96(39.7)$ \\
\hline & $\begin{array}{l}\text { Higher (at least bachelor } \\
\text { degree) }\end{array}$ & $24(9.9)$ \\
\hline & Lack of data & $10(4.1)$ \\
\hline \multirow{5}{*}{$\begin{array}{l}\text { Length of } \\
\text { institutionalization }\end{array}$} & Less than one year & $34(14.0)$ \\
\hline & Between 1 and 5 years & $88(36.4)$ \\
\hline & Between 5 and 10 years & $63(26.0)$ \\
\hline & More than ten years & $53(21.9$ \\
\hline & Lack of data & $4(1.7)$ \\
\hline \multirow[t]{2}{*}{ MMSE } & $15-23$ points & $\begin{array}{l}161 \\
(66.5)\end{array}$ \\
\hline & 24-30 points & $81(33.5)$ \\
\hline \multirow[t]{3}{*}{$\mathrm{Bl}$} & 0-20 points & $24(9.9)$ \\
\hline & $21-80$ points & $\begin{array}{l}129 \\
(53.3)\end{array}$ \\
\hline & Above 80 points & $89(36.8)$ \\
\hline \multirow[t]{3}{*}{ GDS } & $0-5$ points & $86(35.5)$ \\
\hline & $6-10$ points & $\begin{array}{l}126 \\
(52.1)\end{array}$ \\
\hline & Above 10 points & $30(12.4)$ \\
\hline
\end{tabular}

Note. MMSE Mini Mental State Examination, BI Barthel Index, GDS Geriatric Depression Scale

Cluster 3 subjects $(n=72)$ had mean MMSE scores of $18.3 \pm 3.1(p<0.001$ vs. cluster $1 \& 2)$, mean BI $-30.6 \pm$ 18.8 points $(p<0.001$ vs. cluster $1 \& 2)$ and mean GDS $-7.6 \pm 2.3(p<0.001$ vs. cluster $1 \& 2)$. Only one participant in that group had their MMSE result within the normal range. Most subjects of cluster 3 had MMSE scores below 20 points $(n=50,69.4 \%)$. The maximum $\mathrm{BI}$ of that cluster was 65 points, and 61 subjects (84.7\%) had symptoms of depression (GDS score $\geq 6$ points).

For the length of institutionalization, no significant difference was observed between the clusters (cluster 1: mean $73.2 \pm 65.2$ months, cluster 2: mean $76.2 \pm 67.9$ months, cluster 3: mean $69.1 \pm 66.7$ months). However, subjects in cluster 3 were slightly older in comparison with those of cluster 1 (mean $84.4 \pm 6.5$ years vs $82.0 \pm$ 5.8 years; $p=0.049$ ); the age difference vs cluster 2 (mean $82.5 \pm 5.9$ years) was not significant.

\section{Met and unmet needs in the clusters}

Each cluster had a distinct pattern of needs. The number of needs differed significantly between the clusters. The total number of needs was lowest in cluster 1 and highest in cluster $3(p<0.001)$. Similar results were observed for met needs $(p<0.001)$. The number of unmet needs differed significantly between clusters 1 and 3 ( $p=$ 0.015 ); between clusters 2 and 3, only a trend was observed $(p=0.056)$. Detailed characteristics of needs are presented in Table 2.

Characteristics of met needs within the clusters are presented in Table 3. Clusters 1 and 2 differed significantly in four areas, whereas clusters 1 and $3-$ in as many as 11 areas.

The comparison of unmet needs in analyzed clusters is shown in Table 4 (only for the areas in which $\geq 10 \%$ of subjects had unmet needs). In the area Daytime activities, the subjects of cluster 3 had more unmet needs in comparison with both cluster 1 and $2(p=0.023$ and $p=$ 0.003 , respectively). There were also differences in the areas Eyesight/hearing/communication (cluster 2 vs. cluster 3, $p=0.022$ ) and Psychological distress (cluster 1 vs. cluster $3, p=0.032$ ).

\section{Discussion}

The usefulness of CANE for the assessment of needs in residents of LTC institutions has been demonstrated previously $[16,18,19]$. The overall number of needs in these individuals was reported to be higher than in those living in the community [30,31]. These observations are in agreement with our results showing that the mean number of needs reached almost eleven.

We found that, despite a high number of total needs, only a few were unmet, which suggests good quality care was being provided. Van der Ploeg et al. [32] likewise suggested that low numbers of unmet needs were due to the appropriateness of care provision. The unmet needs

Table 2 The characteristics of needs in analyzed clusters

\begin{tabular}{|c|c|c|c|}
\hline & $\begin{array}{l}\text { Number of met needs } \\
\text { means } \pm S D\end{array}$ & $\begin{array}{l}\text { Number of unmet needs } \\
\text { means } \pm S D\end{array}$ & $\begin{array}{l}\text { Number of all needs } \\
\text { means } \pm S D\end{array}$ \\
\hline Cluster 1 & $8.2 \pm 2.7$ & $0.7 \pm 1.0$ & $8.9 \pm 2.7$ \\
\hline Cluster 2 & $\begin{array}{l}10.0 \pm 3.2 \\
p<0.001 \text { vs. cluster } 1\end{array}$ & $0.8 \pm 1.1$ & $\begin{array}{l}10.8 \pm 3.1 \\
p<0.001 \text { vs. cluster } 1\end{array}$ \\
\hline Cluster 3 & $\begin{array}{l}12.1 \pm 3.1 \\
p<0.001 \text { vs. cluster } 1 \& 2\end{array}$ & $\begin{array}{l}1.2 \pm 1.5 \\
p=0.015 \text { vs. cluster } 1 \\
p=0.056 \text { vs. cluster } 2\end{array}$ & $\begin{array}{l}13.3 \pm 2.0 \\
p<0.001 \text { vs. cluster } 1 \& 2\end{array}$ \\
\hline
\end{tabular}


Table 3 Detailed characteristics of met needs in analyzed clusters

\begin{tabular}{|c|c|c|c|c|c|}
\hline Area & & $\begin{array}{l}\text { Cluster } 1 \\
n=83\end{array}$ & $\begin{array}{l}\text { Cluster } 2 \\
n=87\end{array}$ & $\begin{array}{l}\text { Cluster } 3 \\
n=72\end{array}$ & \\
\hline 1 & Accommodation & $73(88 \%)$ & $75(86 \%)$ & $69(96 \%)$ & NS \\
\hline 2 & Looking after the home & 77 (93\%) & $86(99 \%)$ & $72(100 \%)$ & 1 vs. $3 p=0.031$ \\
\hline 3 & Food & $79(95 \%)$ & $84(97 \%)$ & $71(99 \%)$ & NS \\
\hline 4 & Self-care & $46(55 \%)$ & $61(70 \%)$ & $72(100 \%)$ & $\begin{array}{l}1 \text { vs. } 3 p<0.001 \\
2 \text { vs. } 3 p<0.001\end{array}$ \\
\hline 5 & Caring for someone else & $1(1 \%)$ & $2(2 \%)$ & $1(1 \%)$ & NS \\
\hline 6 & Daytime activities & $27(33 \%)$ & $43(49 \%)$ & $48(67 \%)$ & $\begin{array}{l}1 \text { vs. } 2 p=0.030 \\
1 \text { vs. } 3 p<0.001 \\
2 \text { vs. } 3 p=0.036\end{array}$ \\
\hline 7 & Memory & $24(29 \%)$ & $37(43 \%)$ & $50(69 \%)$ & $\begin{array}{l}1 \text { vs. } 3 p<0.001 \\
2 \text { vs. } 3 p<0.001\end{array}$ \\
\hline 8 & Eyesight/hearing/communication & $37(45 \%)$ & $52(60 \%)$ & $52(72 \%)$ & 1 vs. $3 p<0.001$ \\
\hline 9 & Mobility/falls & $37(45 \%)$ & $53(61 \%)$ & $63(88 \%)$ & $\begin{array}{l}1 \text { vs. } 2 p=0.045 \\
1 \text { vs. } 3 p<0.001 \\
2 \text { vs. } 3 p<0.001\end{array}$ \\
\hline 10 & Continence & $33(40 \%)$ & $51(59 \%)$ & $69(96 \%)$ & $\begin{array}{l}1 \text { vs. } 2 p=0.015 \\
1 \text { vs. } 3 p<0.001 \\
2 \text { vs. } 3 p<0.001\end{array}$ \\
\hline 11 & Physical health & 77 (93\%) & $82(94 \%)$ & $68(94 \%)$ & NS \\
\hline 12 & Drugs & $18(22 \%)$ & $25(29 \%)$ & $30(42 \%)$ & 1 vs. $3 p=0.009$ \\
\hline 13 & Psychotic symptoms & $11(13 \%)$ & $17(20 \%)$ & $14(19 \%)$ & NS \\
\hline 14 & Psychological distress & $26(31 \%)$ & $33(38 \%)$ & $31(43 \%)$ & NS \\
\hline 15 & Information & $16(19 \%)$ & $31(36 \%)$ & $28(39 \%)$ & $\begin{array}{l}1 \text { vs. } 2 p=0.025 \\
1 \text { vs. } 3 p=0.008\end{array}$ \\
\hline 16 & Deliberate self-harm & $3(4 \%)$ & $10(11 \%)$ & $10(14 \%)$ & 1 vs. $3 p=0.038$ \\
\hline 17 & Inadvertent self-harm & $2(2 \%)$ & $5(6 \%)$ & $3(4 \%)$ & NS \\
\hline 18 & Abuse/neglect & $3(4 \%)$ & $1(1 \%)$ & $1(1 \%)$ & NS \\
\hline 19 & Behavior & $6(7 \%)$ & $10(11 \%)$ & $8(11 \%)$ & NS \\
\hline 20 & Alcohol & $3(4 \%)$ & $3(3 \%)$ & $2(3 \%)$ & NS \\
\hline 21 & Company & $23(28 \%)$ & $26(30 \%)$ & $31(43 \%)$ & NS \\
\hline 22 & Intimate relationship & $3(4 \%)$ & $3(3 \%)$ & $1(1 \%)$ & NS \\
\hline 23 & Money/budgeting & $40(48 \%)$ & $55(63 \%)$ & $59(82 \%)$ & 1 vs. $3 p=0.002$ \\
\hline 24 & Benefits & 18 (22\%) & 26 (30\%) & 15 (21\%) & NS \\
\hline
\end{tabular}

Table 4 Detailed characteristics of unmet needs in analyzed clusters (the areas in which more than 10\% of subjects had unmet needs)

\begin{tabular}{|c|c|c|c|c|c|}
\hline Area & & $\begin{array}{l}\text { Cluster } 1 \\
n=83\end{array}$ & $\begin{array}{l}\text { Cluster } 2 \\
n=87\end{array}$ & $\begin{array}{l}\text { Cluster } 3 \\
n=72\end{array}$ & \\
\hline 6 & Daytime activities & $5(6 \%)$ & $6(7 \%)$ & $17(24 \%)$ & $\begin{array}{l}2 \text { vs. } 3 p=0.023 \\
1 \text { vs. } 3 p=0.003\end{array}$ \\
\hline 8 & Eyesight/hearing/communication & $11(13 \%)$ & $5(6 \%)$ & $13(18 \%)$ & 2 vs. $3 p=0.022$ \\
\hline 14 & Psychological distress & $9(11 \%)$ & $15(17 \%)$ & $18(25 \%)$ & 1 vs. $3 p=0.032$ \\
\hline 21 & Company & $9(11 \%)$ & $19(22 \%)$ & $13(18 \%)$ & NS \\
\hline 22 & Intimate relationship & $9(11 \%)$ & 7 (8\%) & $13(18 \%)$ & NS \\
\hline
\end{tabular}


we observed had similar patterns of distribution to those reported previously in nursing homes [19].

In our study, LTC residents were grouped using cluster analysis based on their cognitive, functional and psychological status (assessed with MMSE, BI, and GDS) with regard to their needs (assessed with CANE). As the scores used for the assessment of the functional and psychological status of a person do not change proportionally to each other $[19,33]$, it is right that they are included as independent factors in the analysis. To the best of our knowledge, such an analysis has not been done before. Each of the recognized clusters identified a group of subjects with a distinct profile of physical dependency, cognitive status, symptoms of depression, and pattern of needs. In the care practice, the distinction of such groups of residents allows for accurate allocation of human and material resources to match the residents' needs at both individual and group levels.

Cluster 1 subjects had the lowest number of needs, were functionally independent and cognitively intact, with few depressive symptoms. Still, they had almost nine needs, and most of these were met. The number of needs in this cluster reflects the factors leading to placement in an LTC institution [34]. Residents within this group should be evaluated periodically to assess if they really need to stay in LTC units or should rather be provided with intermediate care of appropriate intensity. The development of alternative intermediate care settings, which allow flexibility of the degree of care, is recommended [34].

The presence of depressive symptoms was the common denominator of our cluster 2 subjects. The group in this cluster had more met needs than those in cluster 1 , which indicates higher use of care resources. The residents of LTC settings often have difficulty finding purpose in life, which can lead to the development of depressive symptoms and a declining ability to perform activities of daily living [35]. The distinction of this cluster signals the importance of recognizing and treating depression, as it impacts both independence [36] and needs [19]. Certainly, some of these subjects may require pharmacological treatment of their depression, but a significant number can be helped through non-pharmacological interventions, which may restore meaningfulness in their lives. According to the evidence, non-pharmacological interventions had positive effects on depressive [37] and cognitive [38] symptoms in older adults. Providing appropriate interventions means some residents could potentially move category from cluster 2 to cluster 1 (thereby reducing their care requirements).

Cluster 3, which constitutes the core group of LTC clients, consists of subjects with higher cognitive and physical impairments. They had more needs, both met and unmet than those in the other two clusters. This is consistent with a previous study, which found that the number of needs correlated with functional impairment [17]. A strong negative correlation between the sum of met and unmet needs and the BI has also previously been found [33]. Individuals in our cluster 3 had significantly more unmet needs in the area Daytime activities than those in clusters 1 and 2. This indicates the need to include residents in increased activities tailored to the individuals' abilities [39] and enable the residents to participate actively [40]. Examples comprise involving residents in everyday chores, which are commonly associated with normality [41]. Such an approach sensitizes the staff to view the resident as a whole person, not just a set of limitations to be cared for [42]. The mental wellbeing of subjects with dementia is significant, as lower mood rather than the level of dependency has a greater influence on residents' quality of life [43], and dementia also appears to be one of the most important factors contributing to functional decline in nursing home residents [44].

The limitations of our study result from the fact that we analyzed individuals who were cognitively well functioning alongside those with symptoms of moderate dementia and excluded those with symptoms of severe and moderately severe dementia. The needs of residents with more advanced dementia are complex and may include palliative care needs, which should be investigated separately. The cross-sectional design of our study additionally means that the results may point toward important relationships but cannot imply causality. Also, the generalizability of findings may be limited due to the sample size and the variability of the prevalence of severe dementia in LTC facilities between countries. However, the strength of the study is the inclusion of "older old" subjects, aged 75 years or more, who constitute a more demanding subgroup than the "younger old" as far as care delivery in LTC institutions is concerned, and who are often underrepresented in studies with older adults.

\section{Conclusion}

Our study presents a novel approach to the assessment and categorization of LTC residents. The method of cluster analysis was effective in identifying groups of residents for whom intervention was possible to improve their functioning and subsequently decrease the number of needs. It provides a better understanding of complex relationships between the functional and psychological status and the needs of the residents. The insights gained allow for better focused, tailored care delivery and more appropriate, personalized interventions. This method could also be useful for individuals newly admitted to LTC settings, enabling them to be assigned the appropriate care package. 
The gains from our work are thus two-fold: scientific (moving forward the understanding of the structure of LTC units' residents, and inspiring further investigations in this matter), and practical (the persons in charge of LTC acquire valuable information regarding the residents, especially in the context of identification of clusters for which targeted and optimized care can be provided). Yet, for generalized recommendations regarding care optimization in various regional perspectives, external validation studies are necessary.

\section{Abbreviations}

BI: Barthel Index; CANE: Camberwell Assessment of Need for the Elderly; GDS: Geriatric Depression Scale; LTC: Long term care; MMSE: Mini-Mental State Examination

\section{Acknowledgments}

We would like to thank the researchers involved in data collection for the analyzed database: A. Dymek-Sroczyńska M.Sc., H. Kachaniuk. Ph.D., J. Lewko, Ph.D., J. Mazurek, M.D., Ph.D., Prof. J. Rymaszewska, M.D., Ph.D.

\section{Authors' contributions}

ST and KWT made substantial contributions to the conception. ST, KJ and KWT designed the study. ST, KJ and SK performed the data analysis. SK contributed to the data presentation, ST, JH and AS drafted the manuscript. ST, DT and AS revised the manuscript for critical intellectual content. All authors read, revised and approved the final manuscript.

\section{Funding}

This work was supported by the National Committee for Scientific Research, Poland (grant number N N404 520738). There was no involvement of the funding source in the design of the study and collection, analysis, and interpretation of data and in writing the manuscript.

\section{Availability of data and materials}

All datasets used and analyzed during the current study are property of Poznan University of Medical Sciences, Poznan, Poland. The database is available from the corresponding author on reasonable request.

\section{Declarations}

\section{Ethics approval and consent to participate}

The project was approved by the National Committee for Scientific Research and the Bioethics Committee of Poznan University of Medical Sciences, Poznan, Poland. The study protocol has been previously described in detail [18]. The current analysis is based on its database, owned by Poznan University of Medical Sciences. All studied subjects gave written informed consent after receiving a full explanation of the nature of the study.

\section{Consent for publication}

Not applicable.

\section{Competing interests}

The authors declare that they have no competing interests.

\section{Author details}

${ }^{1}$ Department of Occupational Therapy, Poznan University of Medical Sciences, ul. Swiecickiego 6, 60-781 Poznan, Poland. ${ }^{2}$ Chair of Nursing Poznan University of Medical Sciences, ul. Smoluchowskiego 11, 60-179 Poznan, Poland. ${ }^{3}$ Geriatrics Unit, Chair and Department of Palliative Medicine, Poznan University of Medical Sciences, Poznan, Poland. ${ }^{4}$ Chair of Preventive Medicine, Poznan University of Medical Sciences, ul. Swiecickiego 6, 60-781 Poznan, Poland. ${ }^{5}$ Division of Nursing, School of Health Sciences, City, University of London, Northampton Square, London ECIV OHB, UK. ${ }^{6}$ Department of Mental Health, Chair of Psychiatry, Poznan University of Medical Sciences, ul. Szpitalna 27/33, 60-572 Poznan, Poland.
Received: 6 August 2020 Accepted: 4 May 2021

Published online: 17 May 2021

\section{References}

1. Young Y. Factors associated with permanent transition from independent living to nursing home in a continuing care retirement community. J Am Med Dir Assoc. 2009;10(7):491-7. https://doi.org/10.1016/j.jamda.2009.03.019.

2. Ibrahim SAS, Dahlan A. Engagement in occupational activities and purpose in life amongst older people in the community and institutions. Procedia Soc Behav Sci. 2015;202:263-72. https://doi.org/10.1016/j.sbspro.2015.08.230.

3. Krizaj T, Warren A, Slade A. "Holding on to what I do": experiences of older Slovenians moving into a care home. Gerontologist. 2018;58(3):512-20. https://doi.org/10.1093/geront/gnw150.

4. Lofqvist C, Granbom M, Himmelsbach I, Iwarsson S, Oswald F, Haak M. Voices on relocation and aging in place in very old age--a complex and ambivalent matter. Gerontologist. 2013;53(6):919-27. https://doi.org/10.1 093/geront/gnt034.

5. Cooney A. 'Finding home': a grounded theory on how older people 'find home' in long-term care settings. Int J Older People Nursing. 2012;7(3):18899. https://doi.org/10.1111/j.1748-3743.2011.00278.x.

6. Vaismoradi M, Wang IL, Turunen H, Bondas T. Older people's experiences of care in nursing homes: a meta-synthesis. Int Nurs Rev. 2016;63(1):111-21. https://doi.org/10.1111/inr.12232.

7. Theurer K, Mortenson WB, Stone R, Suto M, Timonen V, Rozanova J. The need for a social revolution in residential care. J Aging Stud. 2015;35:20110. https://doi.org/10.1016/j.jaging.2015.08.011.

8. Behuniak SM. Toward a political model of dementia: power as compassionate care. J Aging Stud. 2010;24(4):231-40. https://doi.org/10.101 6/j.jaging.2010.05.003.

9. London: Alzheimer's Society. Alzheimer's society low expectations: attitudes on choice, care and community for people with dementia in care homes https://www.alzheimers.org.uk/download/downloads/id/1628/alzheimers_ society_low_expectations_report.pdf 2013

10. Toot S, Swinson T, Devine M, Challis D, Orrell M. Causes of nursing home placement for older people with dementia: a systematic review and metaanalysis. Int Psychogeriatr. 2017;29(2):195-208. https://doi.org/10.1017/S1041 610216001654

11. American Geriatrics Society Expert Panel on Person-Centered Care. Personcentered care: a definition and essential elements. J Am Geriatr Soc. 2016; 64(1):15-8. https://doi.org/10.1111/jgs.13866.

12. Fazio S, Pace D, Flinner J, Kallmyer B. The fundamentals of person-centered care for individuals with dementia. Gerontologist. 2018;58(suppl_1):S10-S9.

13. Sverdrup K, Bergh S, Selbaek G, Roen I, Kirkevold O, Tangen GG. Mobility and cognition at admission to the nursing home - a cross-sectional study. BMC Geriatr. 2018;18(1):30. https://doi.org/10.1186/s12877-018-0724-4.

14. Tanuseputro P, Hsu A, Kuluski K, Chalifoux M, Donskov M, Beach S, et al. Level of need, Divertibility, and outcomes of newly admitted nursing home residents. J Am Med Dir Assoc. 2017;18(7):616-23. https://doi.org/10.1016/j.ja mda.2017.02.008.

15. Van Haitsma KS, Curyto K, Abbott KM, Towsley GL, Spector A, Kleban M. A randomized controlled trial for an individualized positive psychosocial intervention for the affective and behavioral symptoms of dementia in nursing home residents. J Gerontol B Psychol Sci Soc Sci. 2015;70(1):35-45. https://doi.org/10.1093/geronb/gbt102.

16. Orrell M, Hancock G. CANE: camberwell assessment of need for the elderly. A needs assessment for older mental health service users. London: Gaskell; 2004.

17. Martin MD, Hancock GA, Richardson B, Simmons P, Katona C, Mullan E, et al An evaluation of needs in elderly continuing-care settings. Int Psychogeriatr. 2002;14(4):379-88. https://doi.org/10.1017/S1041610202008578.

18. Wieczorowska-Tobis K, Talarska D, Kropinska S, Jaracz K, Tobis S, Suwalska A, et al. The Camberwell assessment of need for the elderly questionnaire as a tool for the assessment of needs in elderly individuals living in long-term care institutions. Arch Gerontol Geriatr. 2016;62:163-8. https://doi.org/10.101 6/j.archger.2015.10.005.

19. Ferreira AR, Dias CC, Fernandes L. Needs in nursing homes and their relation with cognitive and functional decline, behavioral and psychological symptoms. Front Aging Neurosci. 2016;8(72):72.

20. Tobis S, Wieczorowska-Tobis K, Talarska D, Pawlaczyk M, Suwalska A. Needs of older adults living in long-term care institutions: an observational study using Camberwell assessment of need for the elderly. Clin Interv Aging. 2018;13:2389-95. https://doi.org/10.2147/CIA.S145937. 
21. Abdi S, Spann A, Borilovic J, de Witte L, Hawley M. Understanding the care and support needs of older people: a scoping review and categorisation using the $\mathrm{WHO}$ international classification of functioning, disability and health framework (ICF). BMC Geriatr. 2019;19(1):195. https://doi.org/10.1186/ s12877-019-1189-9.

22. Rousseaux M, Seve A, Vallet M, Pasquier F, Mackowiak-Cordoliani MA. An analysis of communication in conversation in patients with dementia. Neuropsychologia. 2010;48(13):3884-90. https://doi.org/10.1016/j. neuropsychologia.2010.09.026.

23. Mahoney FI, Barthel DW. Functional evaluation: the Barthel index. Md State Med J. 1965;14:61-5.

24. Chindaprasirt J, Sawanyawisuth K, Chattakul P, Limpawattana P, Tiamkao S, Aountri $P$, et al. Age predicts functional outcome in acute stroke patients with rt-PA treatment. ISRN Neurol. 2013;2013:710681.

25. Yesavage JA, Sheikh J. Geriatric depression scale (GDS). Clin Gerontol. 1986; 5(1-2):165-73. https://doi.org/10.1300/J018v05n01_09.

26. Marc LG, Raue PJ, Bruce ML. Screening performance of the 15-item geriatric depression scale in a diverse elderly home care population. Am J Geriatr Psychiatry. 2008;16(11):914-21. https://doi.org/10.1097/JGP.0b013e318 86 bd67.

27. Folstein MF, Folstein SE, McHugh PR. "Mini-mental state". A practical method for grading the cognitive state of patients for the clinician. J Psychiatr Res. 1975;12(3):189-98. https://doi.org/10.1016/0022-3956(75)90026-6.

28. Mungas D, Marshall SC, Weldon M, Haan M, Reed BR. Age and education correction of mini-mental state examination for English and Spanishspeaking elderly. Neurology. 1996;46(3):700-6. https://doi.org/10.1212/WNL.4 6.3.700.

29. Rymaszewska J, Kłak R, Synak A. Camberwell assessment of need for the elderly (CANE) —badanie polskiej wersji narzędzia. Psychogeriatr Pol. 2008; 5(2):105-13.

30. Miranda-Castillo C, Woods B, Galboda K, Oomman S, Olojugba C, Orrell M. Unmet needs, quality of life and support networks of people with dementia living at home. Health Qual Life Outcomes. 2010;8(1):132. https://doi.org/1 0.1186/1477-7525-8-132.

31. van der Roest HG, Meiland FJ, van Hout HP, Jonker C, Droes RM. Validity and reliability of the dutch version of the Camberwell assessment of need for the elderly in community-dwelling people with dementia. Int Psychogeriatr. 2008; 20(6):1273-90. https://doi.org/10.1017/S1041610208007400.

32. van der Ploeg ES, Bax D, Boorsma M, Nijpels G, van Hout HP. A crosssectional study to compare care needs of individuals with and without dementia in residential homes in the Netherlands. BMC Geriatr. 2013;13(1): 51. https://doi.org/10.1186/1471-2318-13-51.

33. Fernandes L, Goncalves-Pereira M, Leuschner A, Martins S, Sobral M, Azevedo LF, et al. Validation study of the Camberwell assessment of need for the elderly (CANE) in Portugal. Int Psychogeriatr. 2009;21(1):94-102. https://doi.org/10.1017/S1041610208008041.

34. Fahy MA, Livingston GA. The needs and mental health of older people in 24-hour care residential placements. Aging Ment Health. 2001;5(3):253-7. https://doi.org/10.1080/13607860120065050.

35. Fedecostante M, Dell'Aquila G, Eusebi P, Volpato S, Zuliani G, Abete P, et al. Predictors of functional changes in Italian nursing home residents: the U.L.I. S.S.E. study. J Am Med Dir Assoc. 2016;17(4):306-11. https://doi.org/10.1016/ j.jamda.2015.11.004.

36. Burge E, von Gunten A, Berchtold A. Factors favoring a degradation or an improvement in activities of daily living (ADL) performance among nursing home $(\mathrm{NH})$ residents: a survival analysis. Arch Gerontol Geriatr. 2013;56(1): 250-7. https://doi.org/10.1016/j.archger.2012.09.001.

37. Apostolo J, Bobrowicz-Campos E, Rodrigues M, Castro I, Cardoso D. The effectiveness of non-pharmacological interventions in older adults with depressive disorders: a systematic review. Int J Nurs Stud. 2016;58:59-70. https://doi.org/10.1016/j.jinurstu.2016.02.006.

38. Huang HC, Chen YT, Chen PY, Huey-Lan Hu S, Liu F, Kuo YL, et al. Reminiscence therapy improves cognitive functions and reduces depressive symptoms in elderly people with dementia: a meta-analysis of randomized controlled trials. J Am Med Dir Assoc. 2015;16(12):1087-94. https://doi.org/1 0.1016/j.jamda.2015.07.010.

39. Hancock GA, Woods B, Challis D, Orrell M. The needs of older people with dementia in residential care. Int J Geriatr Psychiatry. 2006;21(1):43-9. https:// doi.org/10.1002/gps.1421.

40. Slettebo A, Saeteren B, Caspari S, Lohne V, Rehnsfeldt AW, Heggestad AKT, et al. The significance of meaningful and enjoyable activities for nursing home resident's experiences of dignity. Scand J Caring Sci. 2017;31(4):71826. https://doi.org/10.1111/scs.12386.

41. Edvardsson D, Sandman PO, Rasmussen B. Forecasting the ward climate: a study from a dementia care unit. J Clin Nurs. 2012;21(7-8):1136-14. https:// doi.org/10.1111/j.1365-2702.2011.03720.x.

42. Schell ES. Nurses' perceptions of elderly patients. Age Ageing. 2001;30(5): 367-8. https://doi.org/10.1093/ageing/30.5.367.

43. Hoe J, Hancock G, Livingston G, Orrell M. Quality of life of people with dementia in residential care homes. Br J Psychiatry. 2006;188(5):460-4. https://doi.org/10.1192/bjp.bp.104.007658.

44. Fedecostante M, Onder G, Eusebi P, Dell'Aquila G, Zengarini E, Carrieri B, et al. Predictors of functional decline in nursing home residents: the shelter project. J Gerontol A Biol Sci Med Sci. 2019;75(8):1600-5. https://doi.org/10.1 093/gerona/glz296.

\section{Publisher's Note}

Springer Nature remains neutral with regard to jurisdictional claims in published maps and institutional affiliations.
Ready to submit your research? Choose BMC and benefit from:

- fast, convenient online submission

- thorough peer review by experienced researchers in your field

- rapid publication on acceptance

- support for research data, including large and complex data types

- gold Open Access which fosters wider collaboration and increased citations

- maximum visibility for your research: over $100 \mathrm{M}$ website views per year

At $\mathrm{BMC}$, research is always in progress.

Learn more biomedcentral.com/submissions 